\section{Evaluating Calibrachoa (Calibrachoa $\times$ hybrida Cerv.) Genotype Sensitivity to Iron Deficiency at High Substrate pH}

\author{
Ryan W. Dickson \\ University of New Hampshire Cooperative Extension, University of New \\ Hampshire Department of Biological Sciences, Durham, NH 03824
}

Paul R. Fisher ${ }^{1}$

Institute of Food and Agricultural Sciences, University of Florida, Gainesville, FL 32611

Sonali R. Padhye
PanAmerican Seed, 622 Town Road, West Chicago, IL 60185

William R. Argo

The Blackmore Company, 10800 Blackmore Avenue, Belleville, MI 48111

Additional index words. cluster analysis, floriculture, iron chlorosis, iron efficiency

Abstract. Floriculture crop species that are inefficient at iron uptake are susceptible to developing iron deficiency symptoms in container production at high substrate pH. The objective of this study was to compare genotypes of iron-inefficient calibrachoa (Calibrachoa $\times$ hybrid Cerv.) in terms of their susceptibility to showing iron deficiency symptoms when grown at high vs. low substrate $\mathrm{pH}$. In a greenhouse factorial experiment, 24 genotypes of calibrachoa were grown in peat:perlite substrate at low $\mathrm{pH}(5.4)$ and high pH (7.1). Shoot dry weight, leaf SPAD chlorophyll index, flower index value, and shoot iron concentration were measured after 13 weeks at each substrate $\mathrm{pH}$ level. Of the 24 genotypes, analysis of variance (ANOVA) found that 19 genotypes had lower SPAD and 18 genotypes had reduced shoot dry weight at high substrate $\mathrm{pH}$ compared with SPAD and dry weight at low substrate $\mathrm{pH}$. High substrate $\mathrm{pH}$ had less effect on flower index and shoot iron concentration than the $\mathrm{pH}$ effect on SPAD or shoot dry weight. No visual symptoms of iron deficiency were observed at low substrate $\mathrm{pH}$. Genotypes were separated into three groups using $k$-means cluster analysis, based on the four measured variables (SPAD, dry weight, flower index, and iron concentration in shoot tissue). These four variables were each expressed as the percent reduction in measured responses at high vs. low substrate pH. Greater percent reduction values indicated increased sensitivity of genotypes to high substrate $\mathrm{pH}$. The three clusters, which about represented high, medium, or low sensitivity to high substrate $\mathrm{pH}$, averaged $59.7 \%, \mathbf{4 2 . 8 \%}$, and $25.2 \%$ reduction in SPAD, $47.7 \%, 51.0 \%$, and $39.5 \%$ reduction in shoot dry weight, and $32.2 \%, 9.2 \%$, and $27.7 \%$ reduction in shoot iron, respectively. Flowering was not different between clusters when tested with ANOVA. The least $\mathbf{p H}$-sensitive cluster included all four genotypes in the breeding series 'Calipetite'. 'Calipetite' also had low shoot dry weight at low substrate $\mathrm{pH}$, indicating low overall vigor. There were no differences between clusters in terms of their effect on substrate $\mathrm{pH}$, which is one potential plant iron-efficiency mechanism in response to low iron availability. This experiment demonstrated an experimental and statistical approach for plant breeders to test sensitivity to substrate $\mathrm{pH}$ for iron-inefficient floriculture species.

Floriculture species differ in susceptibility to developing micronutrient disorders, particularly iron and manganese toxicity or deficiency, depending on the efficiency at which micronutrients are taken up by plant

Received for publication 15 June 2016. Accepted for publication 3 Oct. 2016.

We thank PanAmerican Seed, USDA-ARS Floriculture and Nursery Research Initiative no. 583607-8-725, and industry partners of the Floriculture Research Alliance at the University of Florida (floriculturealliance.org) for supporting this research. We also thank James Colee from the University of Florida's Department of Statistics for providing statistical consulting.

${ }^{1}$ Corresponding author. E-mail: pfisher@ufl.edu. at low substrate $\mathrm{pH}$ (Albano and Miller, 1998; Harbaugh, 1995). Marigold (Tagetes erecta L.) cultivars developed different degrees of "leaf bronzing" resulting from toxic iron levels in mature leaves after high micronutrient concentrations were applied to the substrate (Albano and Miller, 1998). Susceptible cultivars of pentas (Pentas lanceolata Benth.) developed lower leaf necrosis at substrate $\mathrm{pH}$ less than 5.5, which was correlated with high tissue iron levels (Harbaugh, 1995).

Cultivars of agronomic crop species grown at high $\mathrm{pH}$ and in calcareous soils are also known to differ in susceptibility to iron deficiency (Fröechlich and Fehr, 1981; Gao and Shi, 2007; Marschner, 1995; Norvell and Adams, 2006). Typical symptoms of iron deficiency include interveinal chlorosis of young shoots and reduced shoot growth during early stages and can progress to severe stunting and shoot tip death in later stages (Marschner, 1995; Römheld, 1987). Symptoms of iron deficiency are well documented for floriculture species, with photos of iron deficiency for a range of floriculture species including calibrachoa published by Argo and Fisher (2002), Gibson et al. (2007), and others.

Strategies for evaluating agronomic crop species for sensitivity to iron deficiency include growing cultivars in noncalcareous and calcareous soils and measuring differences in shoot chlorosis, growth, and yield (Fröechlich and Fehr, 1981; Graham et al., 1992; Hintz et al., 1987; Niebur and Fehr, 1981). Fröechlich and Fehr (1981) used percent reduction in plant height and yield to compare soybean (Glycine max L.) cultivars grown in calcareous vs. noncalcareous soils. Gao and Shi (2007) used hierarchical cluster analysis to group peanut (Arachis hypogaea L.) cultivars by sensitivity to iron chlorosis based on leaf SPAD chlorophyll content, physiologically "active" leaf iron at flowering stage, and pod yield.

Genotypic differences in iron efficiency has not been studied in calibrachoa, which often shows iron deficiency symptoms at high substrate $\mathrm{pH}$ or low iron fertilizer level (Wik et al., 2006). The objective of this study was to compare 24 genotypes of calibrachoa for their sensitivity to showing iron deficiency symptoms (reduced shoot growth, chlorophyll content, tissue iron concentration, and flower number as well as chlorosis and necrosis on new shoots) when grown at high vs. low substrate $\mathrm{pH}$. Twenty of the genotypes were commercial cultivars from four breeding companies, in addition to four experimental genotypes. Eleven genotypes were propagated from seed and the remainder from vegetative cuttings. We hypothesized that differences in sensitivity may be related to the tendency for a genotype to increase $\mathrm{pH}$ and thereby reduce iron solubility, and/or higher demand for iron (milligrams iron per plant, from either a high required iron concentration per unit dry weight, or high vigor in terms of dry weight gain). 
In a greenhouse factorial experiment, seedling plugs and rooted liners of each genotype were transplanted into 11.4-cmdiameter containers and grown for 13 weeks in a soilless peat:perlite substrate at low (initial 5.4) and high (initial 7.1) substrate $\mathrm{pH}$, with analysis of final substrate $\mathrm{pH}$ and substrate-electrical conductivity, leaf SPAD chlorophyll content, total shoot dry weight, tissue iron concentrations, and visual indexes of iron chlorosis symptoms and flower number.

\section{Materials and Methods}

\section{Experimental design}

The experiment was a 24 genotype by two substrate $\mathrm{pH}$ factorial using a randomized complete block design with eight blocks (one replicate per block). Genotypes were grown in plastic azalea containers at one plant per container, and each treatment replicate was an individual container (384 total containers). Blocks were divided evenly between two adjacent, identical greenhouses at one block per greenhouse bench. Greenhouse benches were oriented north to south.

\section{Plant materials and propagation}

On 30 Jan. 2014, 24 genotypes of ironinefficient calibrachoa were transplanted from 128 -count seedling trays into $11.4-\mathrm{cm}$ (4.5-inch)-diameter azalea containers $\left(500 \mathrm{~cm}^{-3}\right.$; Poppelman Plastics US LLC, Claremont, NC) at one plant per container. Twenty genotypes were from six commercial breeding series ('Aloha Kona', 'Cabaret', 'Calipetite', 'Crave', 'Kabloom', and 'Minifamous') in addition to four experimental genotypes. Eleven genotypes were propagated by seed and 13 by vegetative tip cuttings.

Vegetatively propagated genotypes included genotypes of 'Aloha Kona' ('Canary Yellow', 'Milk and Honey', 'True Blue', and 'Dark Red'), 'Cabaret' ('Deep Blue', 'Bright Red', 'Deep Yellow', and 'White 2015'), 'Calipetite' ('Red', 'Blue', 'Yellow', and 'White'), and 'Minifamous Pink 2014'. Seedpropagated genotypes included genotypes of 'Kabloom' ('Blue', 'Deep Pink', 'Denim', 'Red', 'White', and 'Yellow'), 'Crave Sunset', and the remaining experimental genotypes ('E113', 'E144', 'E153', and 'E15597').

\section{Growing conditions and data collection}

The substrate was (v/v) 80\% Canadian Sphagnum peat (Sun Gro Horticulture, Agawam, MA) with long fibers and little dust (Von Post scale 1-2; Puustjarvi and Robertson, 1975 ) and $20 \%$ coarse perlite with preplant fertilizer (in $\mathrm{g} \cdot \mathrm{m}^{-3} 41.7 \mathrm{~N}, 15.3 \mathrm{P}, 63.4 \mathrm{~K}$, $111.2 \mathrm{Ca}, 83.4 \mathrm{~S}, 4.2 \mathrm{Mg}, 0.08 \mathrm{~B}, 0.15 \mathrm{Cu}$, $0.08 \mathrm{Fe}, 0.54 \mathrm{Mn}, 0.15 \mathrm{Mo}$, and $0.46 \mathrm{Zn}$ ) but with no initial liming agent. Nutrients were derived from ammonium nitrate, ammonium phosphate, calcium nitrate, boric acid, copper sulfate, iron ethylenediaminetetraacetic acid (EDTA), magnesium nitrate, manganese sulfate, potassium nitrate, sodium molybdate, and zinc sulfate. Hydrated dolomitic limestone [Graymont Western Lime, Inc., Eden, WI, $97 \% \mathrm{Ca}(\mathrm{OH})_{2} \cdot \mathrm{MgO}$ of which $92 \%$ passed through a $45-\mu \mathrm{m}$ mesh and had an acid neutralizing value of 140 calcium carbonate equivalents (CCEs)] was incorporated at rates of 1.1 and $2.0 \mathrm{~kg} \cdot \mathrm{m}^{-3}$ for initial substrate $\mathrm{pH}$ levels of 5.4 and 7.1, respectively. Substrate $\mathrm{pH}$ levels of 5.4 and 7.1 were considered low and high, respectively, according to the $\mathrm{pH}$ range (5.8 to 6.2) recommended for adequate nutrient availability for most bedding plant species by Peterson (1981). Plants at low pH (5.4) were expected to have adequate micronutrient availability for growth, whereas plants at high $\mathrm{pH}$ (7.1) were expected to develop micronutrient deficiency based on previous reports for calibrachoa (Argo and Fisher, 2002; Gibson et al., 2007). Each container was irrigated with $200 \mathrm{~mL}$ of nutrient solution at transplant. Macronutrients were supplied from a commercial water-soluble fertilizer at (in $\left.\mathrm{mg} \cdot \mathrm{L}^{-1}\right) 150 \mathrm{~N}, 16 \mathrm{P}, 124 \mathrm{~K}, 35 \mathrm{Ca}$, and $9 \mathrm{Mg}$ (GreenCare Fertilizers, Kakankee, IL) where $25 \%$ of total nitrogen was supplied as ammonium $\left(\mathrm{NH}_{4}{ }^{+}-\mathrm{N}\right)$ and the remainder as nitrate $\left(\mathrm{NO}_{3}{ }^{-} \mathrm{N}\right)$. Micronutrients were supplied at (in $\mathrm{mg} \cdot \mathrm{L}^{-1}$ ) $1.0 \mathrm{Fe}, 1.0 \mathrm{~B}, 1.0 \mathrm{Mn}$, $0.5 \mathrm{Zn}, 0.2 \mathrm{Cu}$, and $0.04 \mathrm{Mo}$ derived from $\mathrm{H}_{3}$ $\mathrm{BO}_{3}, \mathrm{MnSO}_{4} \cdot \mathrm{H}_{2} \mathrm{O}, \mathrm{ZnSO}_{4} \cdot 7 \mathrm{H}_{2} \mathrm{O}, \mathrm{CuSO}_{4}$ $\cdot 5 \mathrm{H}_{2} \mathrm{O},\left(\mathrm{NH}_{4}\right)_{6} \mathrm{MoO}_{2} \cdot \mathrm{H}_{2} \mathrm{O}$, and $\mathrm{Fe}(\mathrm{II}) \mathrm{EDTA}$ (13\% Fe; GreenCare Fertilizers). Fertilizer nutrients were derived from the same carriers previously mentioned, mixed in tap water which contained additional fertilizer nutrients (in $\mathrm{mg} \cdot \mathrm{L}^{-1}$ ) at $0.3 \mathrm{P}, 4.3 \mathrm{~K}, 32.2 \mathrm{Ca}$, $22.1 \mathrm{Mg}$, and $42.0 \mathrm{~S}$ and alkalinity of $20.4 \mathrm{mg} \mathrm{HCO}_{3}{ }^{-} / \mathrm{L}$. Plastic saucers placed under each container collected leached solution and allowed for nutrient solution reabsorption following an irrigation event. After the initial irrigation at transplant, the remaining irrigation events consisted of $150 \mathrm{~mL}$ of nutrient solution applied to each container replicate.

On 21 Mar. 2014, all plants were pruned to a uniform height of $7.5 \mathrm{~cm}$ and width of $5.0 \mathrm{~cm}$, and the pruned tissue was dried and saved for measuring total shoot dry weight at final data collection. Flowable Limestone (Limestone F, Clearys, NJ, containing 50\% dolomitic limestone of which $89 \%$ passed through a 200 mesh and with an acid neutralizing value of $56.49 \%$ CCE) was prepared at a 1:75 ratio with tap water and $100 \mathrm{~mL}$ was applied once to each container at high substrate $\mathrm{pH}(\mathrm{pH} 7.1)$ to ensure substrate $\mathrm{pH}$ remained above 6.5. Equivalent volumes of tap water were applied once to each container at low substrate $\mathrm{pH}(\mathrm{pH}$ 5.4). The nutrient solution was modified for the remainder of the experiment by halving the original concentration of all micronutrients, to increase severity of micronutrient-deficiency symptoms.

Plants were harvested for final data collection on 2 May 2014, after a total of 13 weeks. The average daily temperature and daily light integral over the 13 -week period were (mean \pm SD) $20.8 \pm 3.5^{\circ} \mathrm{C}$ and
$9.3 \pm 4.3 \mathrm{~mol} \cdot \mathrm{m}^{-2} \cdot \mathrm{d}^{-1}$ of photosynthetically active radiation, respectively (Watchdog ASeries and Mini Station Model 2475 data loggers; Spectrum Technologies, Inc., Aurora, IL).

Final substrate $\mathrm{pH}$ was measured (Orion Versa Star; ThermoFisher Scientific, Waltham, MA) on composite leachate samples using the pour-through method described by Whipker et al. (2003) for greenhouse container crops. Composite samples consisted of combining leachate from treatment replicates $(\approx 50 \mathrm{~mL}$ leachate per replicate) in adjacent blocks for a total of four composite leachate samples per treatment.

Leaf chlorophyll content was measured nondestructively using a Minolta SPAD meter (Soil Plant Analysis Department; Ramsey, NJ). The SPAD meter indexes leaf chlorophyll content by measuring the ratio of light transmitted through leaves at 750- and 940$\mathrm{nm}$ wavelengths. For this experiment, dark green leaves had SPAD index values greater than 35 , whereas leaves that showed chlorosis had SPAD index values of 30 or less. SPAD data consisted of the average of three SPAD measurements taken from leaves on three separate shoot tips per replicate. Each SPAD measurement was taken on a fully expanded leaf within the top $5.1 \mathrm{~cm}$ of the shoot.

Severity of iron chlorosis was measured for each replicate using a six-point visual index. Chlorosis index values of $0,1,2,3,4$, and 5 indicated shoots showed no symptoms of iron chlorosis, shoots were pale green, $<50 \%$ of shoots showed marginal leaf chlorosis, $<50 \%$ of shoots showed interveinal chlorosis, $>50 \%$ of shoots showed interveinal chlorosis, and shoots were bleached and showed necrosis, respectively.

Flower number was measured for each replicate using a six-point visual index. Flower index values of $0,1,2,3,4$, and 5 indicated that replicates had 0,1 to 5,6 to 10 , 11 to 20,21 to 40 , and $>40$ flowers, respectively. Digital pictures were taken of representative plants with actual flower numbers corresponding to index values and were used as a visual guide to improve consistency in data collection.

Shoot dry weight was measured for each replicate by destructively sampling shoot mass. Shoots were cut at the base of the stem near the substrate, washed with $0.1 \mathrm{~N} \mathrm{HCl}$, rinsed with deionized water, and oven-dried at $70{ }^{\circ} \mathrm{C}$ for $48 \mathrm{~h}$. Shoot dry weight was measured before pruning and was combined with shoot dry weight at the end of the experiment. Dried shoot mass was combined into composite samples the same as previously mentioned for leachate data. Composite samples were ground and analyzed for shoot iron concentration by inductivelycoupled plasma atomic emission spectrophotometry (Karla, 1998) by Quality Analytical Laboratories (Panama City, FL).

Genotype sensitivity to substrate $\mathrm{pH}$ was calculated as the percent reduction in shoot dry weight, leaf SPAD, flower index value, and shoot iron concentration for plants grown at high substrate $\mathrm{pH}$ compared with these 
measurement parameters when plants were grown at low substrate $\mathrm{pH}$ using Eq. [1]. Percent reduction data consisted of eight replicates for shoot dry weight, leaf SPAD, and flower index value and four replicates for shoot iron concentration.

$$
\begin{aligned}
& \text { Percent reduction } \\
& =(1-(\text { value at high } \mathrm{pH} \div \text { value at low } \mathrm{pH})) \\
& \quad \times 100
\end{aligned}
$$

Statistical and cluster analysis. PROC GLIMMIX ANOVA in SAS 9.4 (SAS Institute, Cary, NC) was used to evaluate genotype and substrate $\mathrm{pH}$ effects on absolute values at high and low $\mathrm{pH}$ for leaf SPAD, shoot dry weight, flower index value, iron chlorosis index, and shoot iron concentration. PROC GLIMMIX was also used to analyze genotype main effects on percent reduction ( $\mathrm{pH}$ sensitivity) of leaf SPAD, shoot dry weight, flower index value, and shoot iron concentration. Genotype main effects on substrate $\mathrm{pH}$ were evaluated at high and low pH levels. PROC FASTCLUS $k$-means cluster analysis was used in combination with PROC FREQ to separate genotypes into clusters of high, medium, and low sensitivity to substrate $\mathrm{pH}$. Cluster centroid values were based on genotype least-square means for percent reduction in leaf SPAD, shoot dry weight, flower index value, and shoot iron concentration. ANOVA with PROC GLM was used to evaluate cluster differences in the genotype means for the four clustering measured variables. Tukey's honestly significant difference at $\alpha=0.05$ significance level was used for mean separation in all analyses.

\section{Results and Discussion}

Calibrachoa genotype (24 genotypes tested) interacted with the two substrate $\mathrm{pH}$ levels in terms of shoot dry weight $(P<$ $0.0001)$, leaf SPAD $(P<0.0001)$, flower index value $(P=0.0024)$, and shoot iron concentration $(P<0.0001)$ (least-square means shown in Fig. 1). Analysis of the visual iron chlorosis index also showed an interaction between genotype and substrate $\mathrm{pH}$ level, whereby no obvious leaf discoloration was observed at low substrate $\mathrm{pH}$ but genotypes differed in iron chlorosis index at high $\mathrm{pH}$. Because iron chlorosis index values at high substrate $\mathrm{pH}$ were negatively correlated with leaf SPAD measured at high substrate $\mathrm{pH}\left(R^{2}=0.847\right)$, only SPAD values are reported.

We interpreted a low shoot dry weight at low substrate $\mathrm{pH}$ to indicate a low inherent shoot vigor for a particular genotype. Shoot dry weight ranged from $3.42 \mathrm{~g}$ ('Calipetite Yellow') to $23.56 \mathrm{~g}$ ('Kabloom Deep Pink') at low substrate $\mathrm{pH}$, when micronutrient solubility would not be expected to be limiting to growth. In contrast, we interpreted the shoot dry weight of a genotype grown at high substrate $\mathrm{pH}$, especially in comparison with growth at low $\mathrm{pH}$, to represent shoot vigor under high $\mathrm{pH}$ stress. Shoot dry weight was lower for plants grown at high substrate $\mathrm{pH}$ compared with growth at low $\mathrm{pH}$ for 18 genotypes (Fig. 1A). Shoot dry weight of 'Crave Sunset', 'Cabaret White 2015', and all 'Calipetite' genotypes did not differ between plants grown at high vs. low $\mathrm{pH}$ levels. Genotypes of the 'Calipetite' breeding series overall had the lowest shoot dry weight at both high and low $\mathrm{pH}$.

Leaf SPAD index values were lower at high substrate $\mathrm{pH}$ for 19 genotypes (leastsquare means in Fig. 1B). SPAD at low substrate $\mathrm{pH}$ ranged from 37.9 ('Aloha Kona Canary Yellow') to 51.2 ('E153'). SPAD at high substrate $\mathrm{pH}$ ranged from 15.5 ('Cabaret Red') to 42.3 ('Calipetite Blue'). SPAD values did not differ between substrate $\mathrm{pH}$ levels for the genotypes 'Cabaret Deep Blue', 'Calipetite Red', 'Calipetite Blue', 'Calipetite Yellow', and 'Minifamous Pink 2014'. Genotypes of the 'Calipetite' breeding series overall had the highest SPAD values and darkest green foliage at high substrate $\mathrm{pH}$. 'Calipetite White' was developing symptoms of chlorosis at the end of the experiment, but emerging young leaves were too narrow to measure with the SPAD meter.

Flower index value was lower for seven genotypes at high substrate $\mathrm{pH}$ compared with low $\mathrm{pH}$ (Fig. 1C). Flower index at low substrate $\mathrm{pH}$ ranged from 3.6 ('E15597') to 4.8 ('Aloha Kona Canary Yellow', 'Aloha Kona Dark Red', and 'E113'). At high substrate $\mathrm{pH}$, flower index ranged from 2.8 ('E15597') to 4.1 ('Aloha Kona Canary Yellow' and 'Cabaret Deep Yellow'). Flowering in calibrachoa can be reduced at high substrate $\mathrm{pH}$ and when plants are iron deficient (Fisher et al., 2003).

Shoot iron ranged from (in $\mu \mathrm{g} \mathrm{Fe} / \mathrm{g}$ of dry weight) 49.6 ('E153') to 88.0 ('Calipetite Red') at low substrate $\mathrm{pH}$. Shoot iron levels
A

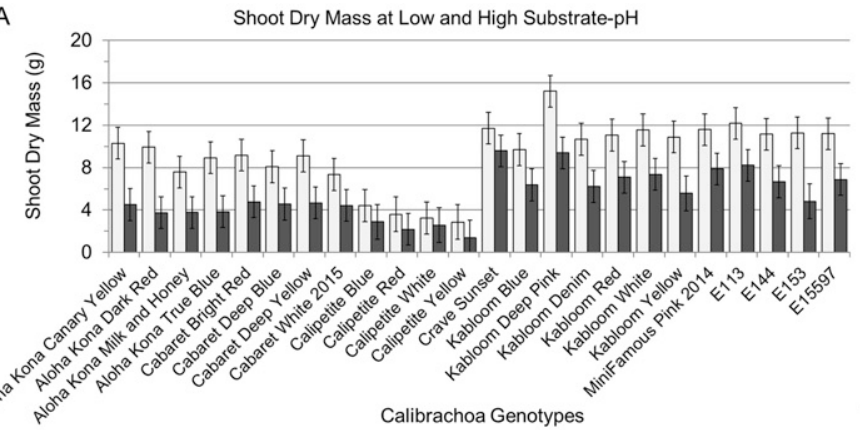

B

Flower Index Value at Low and High Substrate-pH

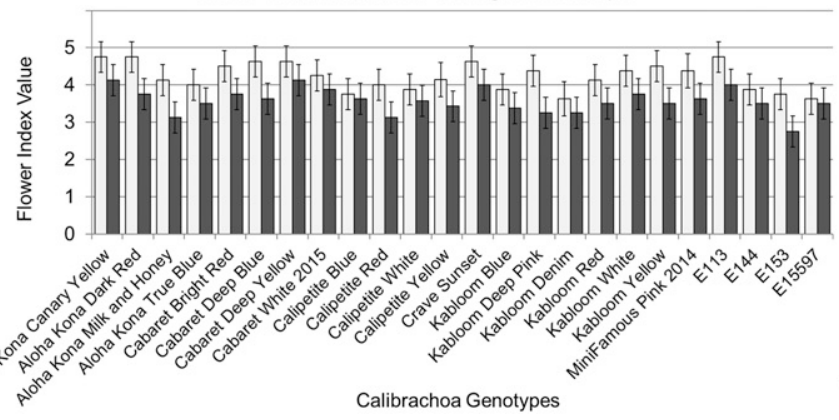

C

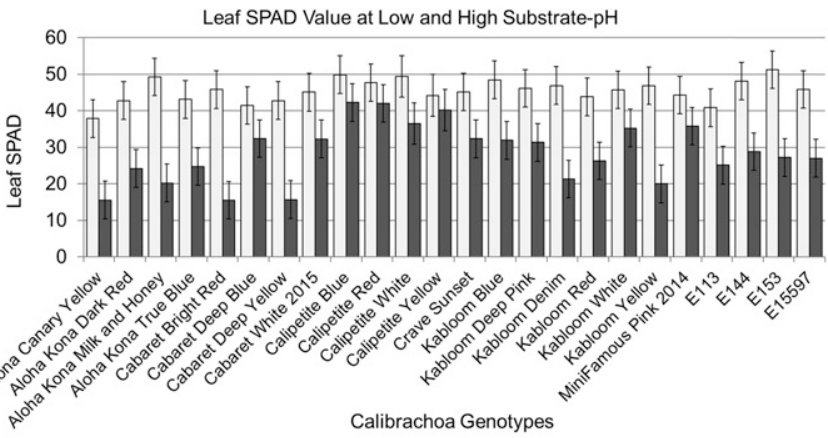

D

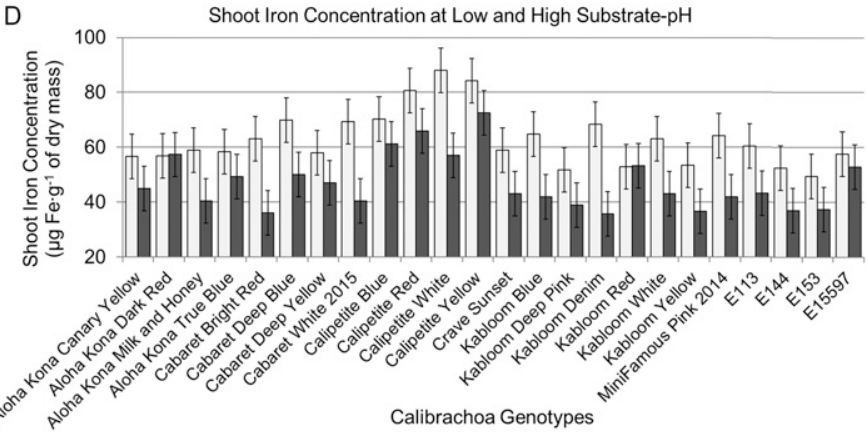

Fig. 1. (A) Shoot dry weight, (B) leaf SPAD chlorophyll content, (C) flower index value, and (D) shoot iron concentration in calibrachoa genotypes grown for 13 weeks at low ( $\mathrm{pH} 5.4$, open bars) and high substrate $\mathrm{pH}(\mathrm{pH} 7.1$, dark bars). Data are least-square means for shoot dry weight $(\mathrm{n}=8)$, leaf SPAD $(\mathrm{n}=8)$, flower index value $(n=8)$, and shoot iron concentration $(n=4)$. Error bars indicate $\pm 95 \%$ confidence intervals using Tukey's honestly significant difference at the $\alpha=0.05$ significance level. 
at low substrate $\mathrm{pH}$ were low compared with the reported iron sufficiency range [61 to $150 \mu \mathrm{g} \mathrm{Fe} / \mathrm{g}$ for calibrachoa from Gibson et al. (2007), or 61 to $150 \mu \mathrm{g} \mathrm{Fe} / \mathrm{g}$ of dry weight, Vetanovetz (1996) for general greenhouse crops]. However, poor correlations between total leaf iron and chlorophyll content have been found in other research (Marschner, 1995; Mengel, 1994) because only a proportion of iron in shoot tissue is physiologically active. In this study, shoot iron was also poorly correlated with leaf
SPAD chlorophyll content (data not shown) and plants at low substrate $\mathrm{pH}$ had dark green foliage. Shoot iron concentration was lower at high substrate $\mathrm{pH}$ compared with plants grown at low $\mathrm{pH}$ for 11 genotypes (Fig. 1D). At high substrate $\mathrm{pH}$, shoot iron concentration ranged from 35.7 ('Kabloom Denim') to 72.5 ('Calipetite Yellow') ( $\mu \mathrm{g} \mathrm{Fe} / \mathrm{g}$ of dry weight). Shoot iron concentration was negatively correlated with shoot dry weight at both low substrate $\mathrm{pH}\left(R^{2}=0.605\right)$ and at high $\mathrm{pH}\left(R^{2}=0.413\right)$. In other words, smaller plants tended to have higher iron concentration. This negative correlation between plant size and iron concentration may have been a nutrient dilution effect in rapidly expanding shoot tissue with more vigorous plants (Marschner, 1995).

Genotypes differed in sensitivity to substrate $\mathrm{pH}$, as quantified by the percent reduction in shoot dry weight $(P=0.0003)$, leaf SPAD $(P<0.0001)$, flower index value $(P=$ $0.0458)$, and shoot iron $(P=0.0006)$ at high substrate $\mathrm{pH}$ compared with low substrate $\mathrm{pH}$
A

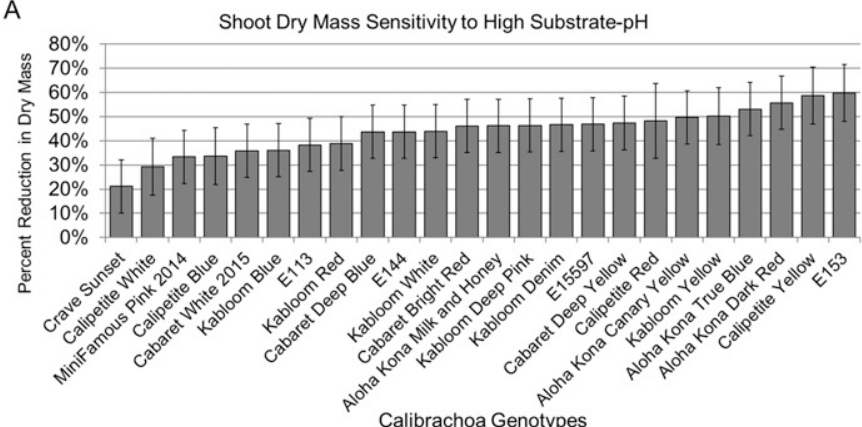

B

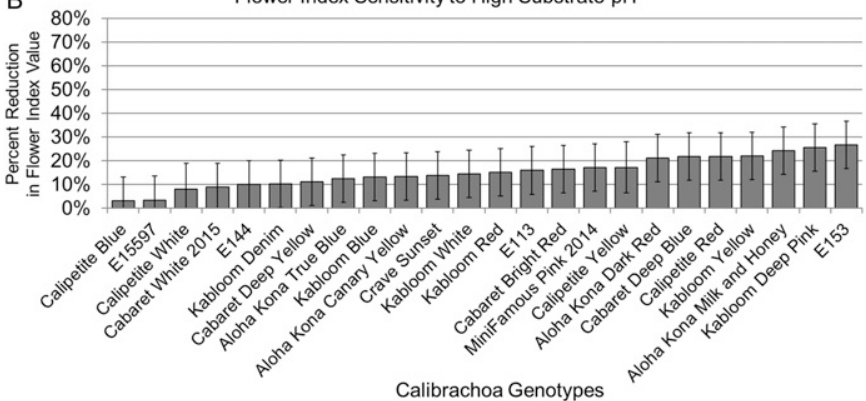

C
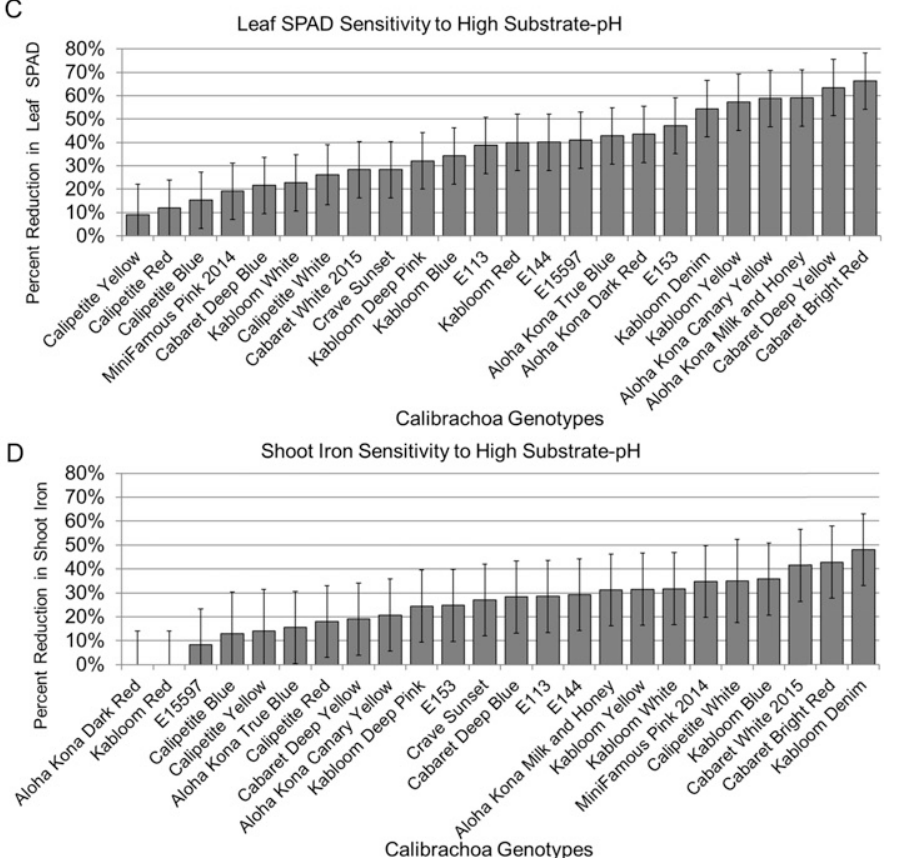

Fig. 2. Genotype sensitivity to substrate $\mathrm{pH}$ quantified as the percent reduction in (A) shoot dry weight, (B) leaf SPAD, (C) flower index value, and (D) shoot iron concentration at high ( $\mathrm{pH}$ 7.1) compared with low (pH 5.4) substrate $\mathrm{pH}$. Genotypes are ordered left to right from lowest to highest sensitivity. Data are leastsquare means for percent reduction in shoot dry weight $(n=8)$, leaf SPAD $(n=8)$, flower index value $(n=8)$, and shoot iron $(n=4)$. Error bars indicate $\pm 95 \%$ confidence intervals using Tukey's honestly significant difference at the $\alpha=0.05$ significance level.

Table 1. Genotypes clustered into groups of about high, medium, and low sensitivity to substrate $\mathrm{pH}$ by luster analysis. Clusters were based on genotype leastsquare means for percent reduction in shoot dry weight, leaf SPAD, flower index value, and shoot iron concentration. Percent reduction at high substrate $\mathrm{pH}$ data are cluster least-square means for percent reduction in leaf SPAD, shoot dry weight, flower index value, and shoot iron concentration. Mean separation used Tukey's honestly significant difference at the $\alpha=0.05$ significance level.

\begin{tabular}{|c|c|c|c|}
\hline \multicolumn{4}{|c|}{ Genotypes clustered by sensitivity to high substrate $\mathrm{pH}$} \\
\hline Percent reduction at high substrate $\mathrm{pH}$ & High sensitivity (cluster 1) & Medium sensitivity (cluster 2) & Low sensitivity (cluster 3 ) \\
\hline Shoot dry weight & $47.7 \% \mathrm{ab}$ & $51.0 \% \mathrm{a}$ & $39.5 \% b^{*}$ \\
\hline \multirow[t]{10}{*}{ Flower index value } & $16.2 \% \mathrm{a}$ & $15.8 \% \mathrm{a}$ & $14.7 \% \mathrm{a}^{\mathrm{NS}}$ \\
\hline & High sensitivity (cluster 1) & Medium sensitivity (cluster 2) & Low sensitivity (cluster 3 ) \\
\hline & Aloha Kona Canary Yellow & Aloha Kona Dark Red & Cabaret White 2015 \\
\hline & Cabaret Deep Yellow & E15597 & Calipetite White \\
\hline & Kabloom Yellow & Kabloom Red & Calipetite Yellow \\
\hline & Kabloom Denim & & Calipetite Blue \\
\hline & & & Crave Sunset \\
\hline & & & E113 \\
\hline & & & E144 \\
\hline & & & Kabloom Deep Pink \\
\hline
\end{tabular}

NS, ${ }^{* * *}, * * *$ Nonsignificant or significant at $P \leq 0.05,0.01$, and 0.001 , respectively. 
(Fig. 2). A greater percent reduction indicated greater sensitivity. Percent reduction ranged from $21.1 \%$ ('Crave Sunset') to $59.9 \%$ ('E153') for shoot dry weight (Fig. 2A), from 9.1\% ('Calipetite Yellow') to $66.3 \%$ ('Cabaret Bright Red') for SPAD (Fig. 2B), from 3.1\% ('Calipetite Blue') to $26.8 \%$ ('E153') for flower index value (Fig. 2C), and from $-1.0 \%$ ('Aloha Kona Dark Red') to 48\% ('Kabloom Denim') for shoot iron concentration (Fig. 2D). Negative values indicated increased shoot iron at high substrate $\mathrm{pH}$ compared with low $\mathrm{pH}$.

Varietal effects on substrate $\mathrm{pH}$ were not correlated with genotype sensitivity to high substrate $\mathrm{pH}$, and therefore substrate $\mathrm{pH}$ data were not shown. Substrate $\mathrm{pH}$ in low $\mathrm{pH}$ treatments remained within the recommended range ( $\mathrm{pH} 5.4$ to 6.2) for calibrachoa (Argo and Fisher, 2002). Only 'Aloha Kona Dark Red' affected substrate $\mathrm{pH}$ in high $\mathrm{pH}$ treatments and had a final substrate $\mathrm{pH}$ of 6.6, whereas all other genotypes had final substrate $\mathrm{pH}$ not different from initial 7.1.

Genotypes were separated into three clusters using $k$-means cluster analysis that corresponded to about high, medium, and low sensitivity to substrate $\mathrm{pH}$ based on percent reduction in leaf SPAD, shoot dry weight, flower index value, and shoot iron concentration (Table 1). Grouping plant species into three $\mathrm{pH}$-management groups is a commonly used strategy for nutrient management (Argo and Fisher, 2002). Three clusters were, therefore, chosen as a practical and manageable number for grouping and evaluating genotypes by differences in sensitivity. The influence of each variable in terms of separating genotypes into clusters was shown by their $R^{2}$ values, which were $0.801,0.452,0.296$, and 0.011 for percent reduction in SPAD, shoot iron, shoot dry weight, and flower index, respectively. ANOVA showed that genotype clusters differed in percent reduction in leaf SPAD $(P<0.0001)$, shoot iron $(P=0.0018)$, and shoot dry weight $(P=$ $0.0250)$, but not percent reduction in flower index $(P=0.8938)$. High, medium, and low sensitivity cluster least-square means were $59.7 \%, 42.8 \%$, and $25.2 \%$ for SPAD, $47.7 \%$, $51.0 \%$, and $39.5 \%$ for shoot dry weight, and $32.2 \%, 9.2 \%$, and $27.7 \%$ for shoot iron (Table 1).

One of several iron-efficiency mechanisms is a drop in substrate $\mathrm{pH}$ by plant roots to increase iron solubility and uptake. However, there was no difference between clusters in terms of their least-square mean substrate $\mathrm{pH}$ at the high lime level (i.e., the high substrate $\mathrm{pH}$ treatment, data not shown). Other iron-efficiency mechanisms were not measured in this experiment, such as physiologically "active" iron levels in shoot tissue, root iron reductase activity, and root efflux of organic compounds which solubilize iron (Albano and Miller, 1996; Bienfait, 1988; Gao and Shi, 2007; Landsberg, 1986; Marschner et al., 1986; Mengel, 1994; Römheld and Marschner, 1983). However, lack of overall plant vigor did appear to reduce sensitivity to $\mathrm{pH}$ under the trial conditions, as illustrated by the 'Calipetite' genotypes in the least $\mathrm{pH}$-sensitive group. 'Calipetite' genotypes had low shoot dry weight at low substrate $\mathrm{pH}$, indicating low overall vigor. Low vigor would reduce total iron requirement per plant, which may have delayed the onset of stunting and chlorosis symptoms at high substrate $\mathrm{pH}$.

The clusters can be visually illustrated in two dimensions by plotting genotypes based on percent reduction in shoot dry weight vs. leaf SPAD (Fig. 3). Manuel and Alcántara (2002) plotted cultivars of pear (Pyrus communis L.), olive (Olea europaea L.), and quince (Cydonia oblonga Mill.) by relative reduction in shoot growth vs. reduction in SPAD to evaluate cultivars for sensitivity to iron deficiency when grown in iron-limited nutrient solution. In Fig. 3A, vertical and horizontal dashed lines indicate median values for percent reduction in shoot dry weight $(46.2 \%)$ and leaf SPAD (39.3\%), respectively, and separate genotypes into 50 th percentile groups. Figure $3 \mathrm{~B}$ shows genotypes clustered by high (solid line), medium (dashed line), and low (dotted line) sensitivity. The irregular shape indicated for 'Kabloom Red', 'E113', and 'E144' occurs because two additional dimensions (shoot iron concentration and flower index) were also used in clustering but are not shown in Fig. 3B.

\section{Conclusions}

Reduced shoot growth and increased chlorosis occurred in calibrachoa grown at high substrate $\mathrm{pH}$, which are common symptoms

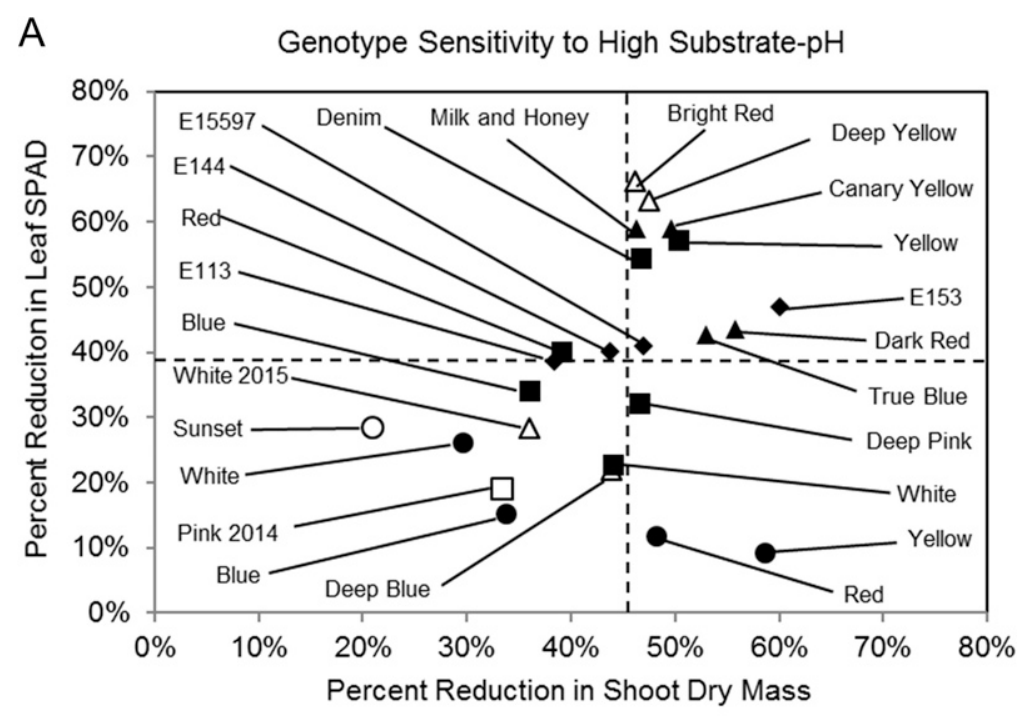

B Genotype Sensitivity to High Substrate-pH

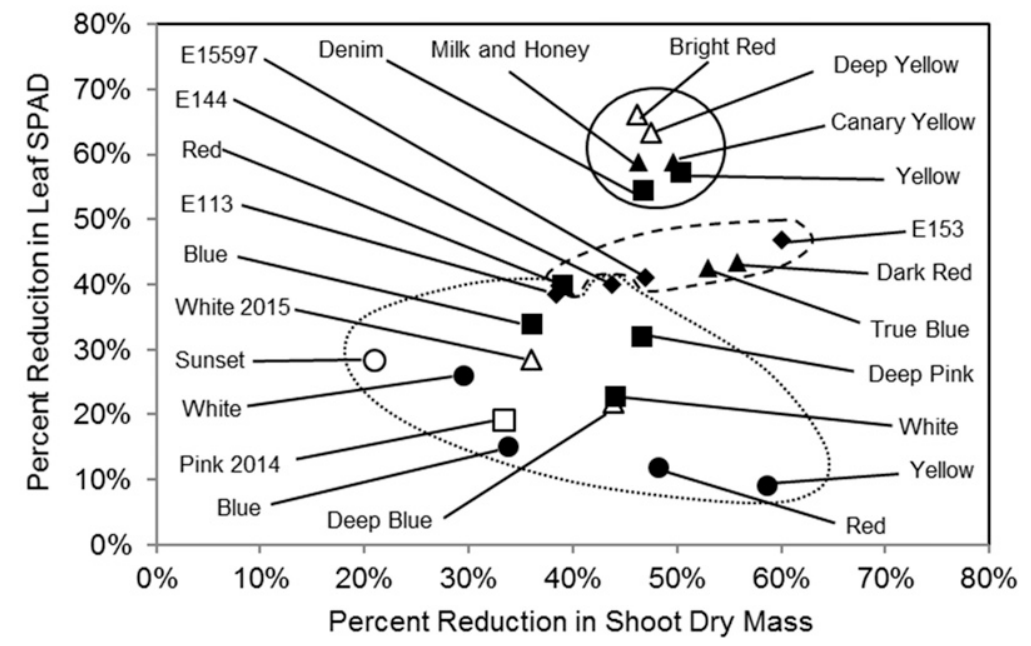

Fig. 3. Genotypes plotted by percent reduction in shoot dry weight ( $x$ axis) vs. percent reduction in leaf SPAD ( $y$ axis). Data represent least-square means of eight replicates. Horizontal and vertical dashed lines in Fig. 3A indicate median values for percent reduction in leaf SPAD (39.3\%) and shoot dry weight $(46.2 \%)$, respectively. Figure 3B groups genotypes with about high (solid line), medium (dashed line), and low (dotted line) sensitivity to substrate $\mathrm{pH}$ from $k$-means cluster analysis. Breeding series is indicated by the data point style ( $\boldsymbol{\Delta}$ = 'Aloha Kona', $\Delta=$ 'Cabaret', $\mathbf{O}=$ 'Calipetite', $\bigcirc=$ 'Crave', $\boldsymbol{\square}=$ 'Kabloom', $\square=$ 'Minifamous', = experimental genotypes). 
of iron deficiency in floriculture species. Genotype sensitivity to substrate $\mathrm{pH}$ was quantified by calculating the percent reduction in shoot vigor, leaf SPAD, flower index value, and shoot iron concentration at high vs. low substrate $\mathrm{pH}$. Genotypes were then grouped into high, medium, and low sensitivity to substrate $\mathrm{pH}$ using a $k$-means cluster analysis approach.

Genotypes with high, medium, and low sensitivity did not differ in the mean substrate $\mathrm{pH}$ at the high substrate $\mathrm{pH}$ treatment, which is one potential plant response influencing iron solubility and uptake. 'Calipetite' genotypes were least vigorous at low substrate $\mathrm{pH}$, but were also the least sensitive to high substrate $\mathrm{pH}$. Further investigation of varietal differences, including the parentage of calibrachoa genotypes and breeding lines, could provide greater guidance for calibrachoa breeding.

This experiment demonstrated an experimental and statistical approach for plant breeders to test genotype sensitivity to substrate $\mathrm{pH}$ for iron-inefficient floriculture species. This approach may also be used for screening genotypes when breeding genetic series with higher $\mathrm{pH}$ tolerance. Plants grown at low substrate $\mathrm{pH}$ where micronutrient solubility is not limiting can be compared with growth at high substrate $\mathrm{pH}$. Measurement variables could include shoot dry weight, SPAD, flower number, and shoot iron concentration, in addition to other horticulturally important parameters. In this experiment, shoot dry weight and leaf SPAD were more sensitive than flower index or shoot iron concentration. Growth at low substrate $\mathrm{pH}$ was useful to compare inherent vigor of genotypes and provided a baseline to compare against growth under high $\mathrm{pH}$ stress. Percent reduction in growth at high vs. low substrate $\mathrm{pH}$ was calculated to indicate relative sensitivity to substrate $\mathrm{pH}$. Cluster analysis using $k$-means provides breeders with a statistical approach to grouping genotypes where each genotype is assigned to only one cluster and clusters can be evaluated using ANOVA. Figure 3 demonstrates a simple and visual method for breeders to evaluate genotypes by shoot vigor and leaf color.

\section{Literature Cited}

Albano, J.P. and W.B. Miller. 1996. Iron deficiency stress influences physiology of iron acquisition in marigold (Tagetes erecta L.). J. Amer. Soc. Hort. Sci. 121:438-441.

Albano, J.P. and W.B. Miller. 1998. Marigold cultivars vary in susceptibility to iron toxicity. HortScience 33:1180-1182.

Argo, W.R. and P.R. Fisher. 2002. Understanding $\mathrm{pH}$ Management for Container-Grown Crops. Meister Publishing, Willoughby, $\mathrm{OH}$

Bienfait, H.F. 1988. Mechanisms in Fe-efficiency reactions of higher plants. J. Plant Nutr. 11: 605-629.

Fisher, P.R., R.M. Wik, B.R. Smith, C.C. Pasian, M. Kmetz-González, and W.R. Argo. 2003. Correcting iron deficiency in calibrachoa grown in a container medium at high $\mathrm{pH}$. HortTechnology 13:308-313.

Fröechlich, D.M. and W.R. Fehr. 1981. Agronomic performance of soybeans with differing levels of iron deficiency chlorosis on calcareous soil. Crop Sci. 21:438-441.

Gao, L. and Y. Shi. 2007. Genetic differences in resistance to iron deficiency chlorosis in peanut. J. Plant Nutr. 30:37-52.

Gibson, J.L., D.S. Pitchay, A.L. Williams-Rhodes, B.E. Whipker, P.V. Nelson, and J.M. Dole. 2007. Nutrient deficiencies in bedding plants. Ball Publishing, Batavia, IL.

Graham, M.J., P.A. Stephens, J.M. Widholm, and C.D. Nickell. 1992. Soybean genotype evaluation for iron deficiency chlorosis using sodium bicarbonate and tissue culture. J. Plant Nutr. 15:1215-1225.

Harbaugh, B.K. 1995. Iron toxicity in Pentas lanceolata. HortTechnology 5:306-307.

Hintz, R.W., W.R. Fehr, and S.R. Cianzio. 1987. Population development for the selection of high-yielding soybean cultivars with resistance to iron-deficiency chlorosis. Crop Sci. 27:707-710.

Karla, Y.P. (ed.). 1998. Handbook of reference methods for plant analysis. Taylor \& Francis Group, LLC, Boca Raton, FL.

Landsberg, E.C. 1986. Function of rhizodermal transfer cells in the $\mathrm{Fe}$ stress response mechanism of Capsicum annuum L. Plant Physiol. 82:511-517.
Lindsay, W.L. 1979. Chemical equilibria in soils. John Wiley and Sons, Inc., Caldwell, NJ.

Manuel, D. and E. Alcántara. 2002. A comparison of ferric-chelate reductase and chlorophyll and growth ratios as indices of selection of quince, pear and olive genotypes under iron deficiency stress. Plant Soil 241:49-56.

Marschner, H. 1995. Mineral nutrition of higher plants, 2nd ed. Academic Press, San Diego, CA.

Marschner, H., V. Römheld, and M. Kissel. 1986. Different strategies in higher plants in mobilization and uptake of iron. J. Plant Nutr. 9:695-713.

Mengel, K. 1994. Iron availability in plant tissuesiron chlorosis on calcareous soils. Plant Soil 165:275-283.

Niebur, W.S. and W.R. Fehr. 1981. Agronomic evaluation of soybean genotypes resistant to iron deficiency chlorosis. Crop Sci. 21:551554

Norvell, W.A. and M.L. Adams. 2006. Screening soybean cultivars for resistance to irondeficiency chlorosis in culture solutions containing magnesium or sodium bicarbonate. J. Plant Nutr. 29:1855-1867.

Peterson, J.C. 1981. Modify your $\mathrm{pH}$ perspective. Florists' Rev. 169:34-36.

Puustjarvi, V. and R.A. Robertson. 1975. Physical and chemical properties, p. 23-38. In: D.W. Robinson and J.G.D. Lamb (eds.). Peat in horticulture. Academic Press, London, UK.

Römheld, V. 1987. Different strategies for iron acquisition in higher plants. Physiol. Plant. 70:231-234.

Römheld, V. and H. Marschner. 1983. Mechanism of iron uptake by peanut plants: I. FeIII reduction, chelate splitting, and release of phenolics. Plant Physiol. 71:949-954.

Vetanovetz, R.P. 1996. Tissue analyses and interpretation, p. 197-220. In: D.W. Reed (ed.). Water, media, and nutrition for greenhouse crops. Ball Publishing, Batavia, IL

Whipker, B.E., T.J. Cavins, J.L. Gibson, J.M Dole, P.V. Nelson, W. Fonteno, and D.A. Bailey. 2003. Water, media, and nutrition testing, p. 47-70. In: D. Hamrick (ed.). Ball Redbook, Crop Production. 17th ed. Vol. 2. Ball Publishing, Batavia, IL.

Wik, R.M., P.R. Fisher, D.A. Kopsell, and W.R. Argo. 2006. Iron form and concentration affect nutrition of container-grown pelargonium and calibrachoa. HortScience 41: 244-251. 